point and also in explaining the mechanics of the growth-stimulating action of antibiotics.

"We hope that the publication of this monograph will assist in developing further theoretical research and a wider application of vitamin $B_{12}$ in clinical work and on livestock with the view that all the valuable qualities of this vitamin may be most fully utilized for the protection of animal health and ensuing material benefits."
In view of the present interest in vitamin $\mathbf{B}_{12}$ I think it would be well worth while if some agency could undertake to provide an English translation of this monograph and also perhaps of the four which preceded it.

I thank Mrs. Pauline Renacre, 205 East 29th Ave., North Vancouver, for her assistance with the translation, and Mrs. A. McCullough, secretary in the Faculty of Agriculture, for help in editing the manuscript.

\title{
GLOBAL FALL-OUT IN AUSTRALIA DURING 1960-61
}

\begin{abstract}
$\mathrm{D}$ URING the years 1960 and 1961, continuous monthly sampling of fall-out over Australia for gross radioactivity was maintained by the Atomic Weapons Tests Safety Committee at eight stations: Perth, Adelaide, Melbourne, Hobart, Sydney, Brisbane, Townsville and Darwin. The Committee's network of 24 stations taking daily samples was closed down in April 1960, when no active samples had been detected for more than a year. In the past, this monitoring progranme, and, especially, the daily sampling, provided information on tropospheric and early stratospheric fall-out over Australia from nuclear weapon tests held overseas. Accordingly, when the Soviet Union resumed testing of high-yield weapons in the atmosphere in September 1961, the daily sampling was recommenced using the 24 -station network to give representative measurements for the regions inhabited by the majority of the Australian population.

The observations of gross radioactivity in fall-out are complementary to data obtained by the Committee in its extensive and continuous survey of strontium- 90 in the Australian environment. Results from this survey to the end of 1960 have already been pub. lished in detail. A report by Drs. J. R. Blake, L. J. Dwyer, J. R. Moroney, D. J. Stevens and Prof. E. W. Titterton* presents the results of total $\beta$-activity measurements on the monthly samples taken from January 1960 until December 1961, and on the daily samples taken from September 15 until December 31, 1961 , following the resumption of weapon testing by the U.S.S.R.

* Austral. J. Sci., 24, No. 12 (June 1962).
\end{abstract}

During the two years for which results are presented, the U.S.S.R. tested about 50 weapons in the atmosphere from September to November 1961; France tested three weapons in the atmosphere over the Sahara Desert in February, April and December 1960; late in September 1961, the United States commenced a new programme of underground testing at the Nevada test site.

The major weapon tests by the U.S.S.R. were carried out in the vicinity of Novaya Zemlya in the Arctic; the United States Atomic Energy Commission has estimated the total explosive yield for the sories to be about 120 megatons and the fission yield at about 25 megatons. This corresponds to an injection of radioactivity into the atmosphere of the northern hemisphere in the order of twice that which resulted from the weapon tests conducted by the U.S.S.R. in the Arctic in October 1958; those tests produced, during 1959, marked increases in radioactivity in the biosphere of the northern, but not of the southern, hemisphere. France tested only low-yield nuclear weapons of estimated total yield considerably less than 1 megaton. No global fall-out has arisen from the underground weapon tests being carried out by the United States.

Results show that the level of total $\beta$-activity in fall-out over Australia continued to decrease during the period 1960-61. The data give no indication of the arrival of debris from the French tests during this period or the major U.S.S.R. series of SeptemberNovember 1961. Some fall-out over Australia of long-lived fission products from these Soviet tests may be expected in the spring of 1962 .

\section{NORWAY INSTITUTE OF ATOMIC ENERGY}

\begin{abstract}
A $\mathrm{N}$ illustrated survey of the work of the Institute A for Atomenergi (IFA) at Kjeller and Halden, Norway, during 1961, together with details of the organization and an abstract of the accounts for the budget year 1961, are given in the recent report*. Mr. Gunnar Randers continued as managing director with Mr. O. R. Kåsa as assistant director and project manager of the Halden Project.

The main facility for physics research and isotope production is the 10-year-old $450-\mathrm{kW}$ (heavy-water reactor Jeep at Kjeller. The reactor, which is operated continuously, except for routine stops for isotope insertion and removal, and the semi-annual inspection

* Institutt for Atomenergi, Kjeller. Survey of Activities, 1961. Pp. 24. (Kjeller: Institutt for Atomenergi, 1962.)
\end{abstract}

of the fuel element canning, released 130.3 MWD of heat during 1961 , bringing the total up to $680.5 \mathrm{MWD}$ since the reactor commenced operation. At the summer inspection the aluminium canning of one fuel element showed several cracks. This was the first time that such damage had been dotected. Various improvements in the reactor system and auxiliary equipment were made during the year. In order to compensate for the neutron loss due to the slightly thicker walls of the new reactor tank installed during 1960 and to improve neutron flux conditions, some fuel elements consisting of 1.7 per cent enriched uranium oxide are to be installed and the first of these, installed in November 1961, has already improved the flux and reactivity conditions. 
The report states that one of the most significant events of the year under review was the commissioning during June, and the official inauguration on November 29, of the zero energy reactor Nora and of the fuel processing pilot plant. The reactor was established as a joint IFA-IAEA undertaking and was designed and built by NOR-ATOM $A / S$. The research programme has been approved by the Nora Committee under its chairman, Dr. R. Ramanna of India. For this programme three fuel charges are available, the first a 3 per cent enriched fuel charge provided by the U.S. Atomic Energy Commission, the second a reference charge of 2.5 tons of natural uranium metal, and the third a charge of elements from the Halden second core. The research programme is concentrated on the physical aspects of spectral shift controlled reactor systems.

In the spring of 1961 the design of the Jeep II reactor was reviewed in order to simplify the design and bring down costs; to introduce a flux trap; and to consider the use of the principle of spectral shift for long-term reactivity control. The reactor will be built and started as a heavy-water reactor and will be housed in a thermally insulated steel containment shell $22.4 \mathrm{~m}$ high and $22 \mathrm{~m}$ in diameter to withstand a pressure of $0.15 \mathrm{~kg} / \mathrm{cm}^{2}$. The erection of the shell and control building was started in the summer of 1961. The reactor will be moderated and cooled by heavy water and fuelled by slightly enriched $\mathrm{UO}_{2}$ canned in aluminium tubes. Jeep $I I$ is planned to go critical during 1965 , and it is estimated that the thermal neutron flux at a power-level of $2 \mathrm{MW}$ in the centre of the reactor will be about $1.5 \times 10^{13}$ neutrons $/ \mathrm{cm}^{2}$ sec.
The experimental programme at the Halden reactor continued with the first fuel charge up to May, when the reactor was shut down prior to the insertion of the second, enriched core. During the second phase of the programme the reactor will be operated at 20 MW instead of $6 \mathrm{MW}$ at $155^{\circ} \mathrm{C}$. The programme so far includes the determination of data on various reactor physics parameters, such as temperature and water-level coefficients, and the critical buckling as a function of moderator temperature has been calculated. Modifications, partly based on experience gained during the operation of the reactor, which will be introduced for operation at the higher power, include the installation of a new steam transformer to be operated in parallel with the original one, and a tertiary loop with a new steam generator for dissipation of the steam produced.

During 1961 two new wings of the NetherlandNorwegian Reactor School were taken into use, thus increasing the capacity of the school considerably by providing facilities for experimental work in reactor engineering, physics and radiochemistry. The nine weeks standard course in fundamentals of nuclear engineering was held twice, and during March a course on analogue computer techniques and their application to nuclear engineering and chemical processing problems was held for the staff at Kjeller and Halden.

The report concludes with details of the safety work and health physics; the technical information service including a list of Kjeller Reports and Halden Project Reports issued during the year; international co-operation; and the numbers and distribution of the staff at the Institute on December 31, 1961.

\section{PUBLICATIONS OF THE NATIONAL PHYSICAL LABORATORY, TEDDINGTON}

\footnotetext{
GOUR new booklets in the series Notes on Applied Science of the National Physical Laboratory, Teddington, have recently been published*. The first, No. 25 in the series, entitled Hydrometers and Hydrometry, deals with basic considerations of air buoyancy, surface tension and the spacing of the scale; the general use of hydrometers with examples; the verification and adjustment of hydrometers with particular reference to practice at the National Physical Laboratory; and types of hydrometer scale and the relationship between scales. It is emphasized that ordinary hydrometers of constant mass are convenient instruments for the measurement of the density and specific gravity of liquids, and that greater accuracy can be obtained by their use than is generally realized. Though British Standard 718: 1960 contains considerable information on hydrometers and hydrometry, several interesting points outside the scope of the Standard are dealt with in the booklet.

* Department of Scientific and Industrial Research. National ${ }^{*}$ Department of Scientific and Industrial
Physical Laboratory. Notes on Applied Science.

No. 25: Hydrometers and Hydrometry. By J. B. Rands and P. H. Bigg. Pp. iv $+31+1$ plate. $28.6 d$. net.

No. 27: Inspection of Gauging Dimensions Involving Linear and Angular Measurements. By Dr. J. C. Evans and C. O. Taylerson. Pp. v+42. 3s. 6d. net.

No. 28: The Measurement of Frequency. By Dr. I. Essen, E. G. Hope and $\mathrm{K}$. Morris. Pp. $\mathrm{v}+17$. $18.9 d$. net.

No. 29: Physical Photometry. By Dr. B. H. Crawford. Pp.iv +16. 18. $9 d$. net.

(London: H.M.S.O., 1962.)
}

The information given in No. 27, Inspection of Gauging Dimensions Involving Linear and Angular Measurements, is intended to assist engineering inspectors in checking gauges, jigs and workpieces, involving combined measurements of length and angle. The use of the Universal Measuring Block manufactured by the Pitter Gauge and Tool Co. Ltd. is described, and full particulars of the measuring equipment associated with it are given together with the types of measurement which can be made with the equipment. A principal purpose of the booklet is to present a general procedure for the type of measurement in which the required dimension must be obtained by calculation from indirect measurements of the work. Examples of both the simpler direct measurement technique and of the indirect measurement procedure are given and fully explained. The derivation of the associated trigonometrical formulæ required in the calculations are set out in an appendix.

Measurements of frequency with an accuracy approaching one part in $10^{10}$ are now required not only for precision laboratory measurements but also for routine operations. The techniques which make such measurements possible are briefly discussed in No. 28 of the series, entitled The Measurement of Frequency, where an account is given also of the more usual types of frequency meter utilizing a resonant 